\title{
Analisys of Immunohistochemical Prognostic Markers in Canine Mammary Cancer and Its Relation to Postsurgical Survival
}

\author{
Francisco Pedraza-Ordoñez ${ }^{1,2}$, Luis Mauricio Montoya-Florez ${ }^{1,2}$,Camilo Bulla ${ }^{3}$, \\ Noeme Sousa Rocha1,4 \\ ${ }^{1}$ Department of Veterinary Clinics, Laboratory of Investigative and Comparative Pathology, School of \\ Veterinary Medicine and Animal Science, Universidade Estadual Paulista FMVZ-UNESP, Sao Paulo, Brazil \\ ${ }^{2}$ Animal Pathology Research Group, Animal Health Department, Universidad de Caldas, \\ Manizales, Colombia \\ ${ }^{3}$ Department of Pathology/Population Medicine-Mississippi, College of Veterinary Medicine Mississippi State \\ University, Starkville, USA \\ ${ }^{4}$ Department of Pathology, Botucatu Medical School, Universidade Estadual Paulista-UNESP, Distrito de \\ Rubião Júnior s/n, Botucatu, Brazil \\ Email: maomontoya53@yahoo.es
}

Received 1 June 2015; accepted 6 July 2015; published 9 July 2015

Copyright (C) 2015 by authors and Scientific Research Publishing Inc.

This work is licensed under the Creative Commons Attribution International License (CC BY).

http://creativecommons.org/licenses/by/4.0/

c) (i) Open Access

\section{Abstract}

Background: Several animal models, including dogs, have been useful to compare the pathogenesis of mammary neoplasm in humans, showing biological parallelism in the growth and development of breast cancer. The causes of cancer could be attributed to change in several tumor suppressor genes. The relationship between molecule associated to senescence and clinical prognosis of patients affected by mammary cancer is little known. Beyond a collection of data, the major interest of the present study was to carry out a clinical follow-up of patients affected by these tumors, through association with new molecular markers by immunohistochemical technic. Upon completing the study, 15 patients survived, while 45 died. In the case of malignant neoplasms, 40 patients died because of the illness. The type of surgery most used by veterinarian surgeons was the simple lumpectomy, followed by the regional mastectomy. Sentinel node was removed by surgery only when clearly affected. Result: Markings against steroid hormones were positive. Regarding the markings against HER2 and Ki-67, they were negative in all cases. The markings against P53 and CD31 were all positives. Markings against molecules associated with cellular senescence were all positives. No statistical differences were found in immunomarcation for the different antigens used as clinical prognosis factors in mammary neoplasms. Conclusions: According 
to the study conditions, the survival of patients affected by breast tumors is directly related to diagnosis and malignancy histological grade, but not to animal breed, number of affected glands or patient reproductive status. On the other hand, immunohistochemical markings were not related to the patient prognosis. For this reason, it is important to highlight the persistance of a high percentage of mammary neoplasm cases clinically diagnosed with poor results on patient survival. Thus, educating owners and veterinarians for using diagnostic available tools to improve the prognosis after surgical animals affected by breast cancer is quite necessary.

\section{Keywords}

\section{Celular Senescence, Prognostic Markers, Immunohistochemical, Mammary Cancer, Animal Model}

\section{Introduction}

Mammary neoplasms are common in female canine, representing up to $82 \%$ of tumors affecting reproductive tract of bitch [1] [2]. Similarly, in humans, malignant tummors cause the death of approximately 300,000 women per year, and the rate of incidence increases [3] [4]. Several animal models, including dogs, have been useful to compare the pathogenesis of this disease in humans, showing biological parallelism in the growth and development of breast cancer. Likewise, some coincidences related to epidemiological, morphological, clinical, pathological, and biochemical features, as well as to the response to chemotherapeutic and surgical treatment, have been reported [5]. Once determined by sequencing the close likeness between canine and human genome, dogs have emerged as an attractive alternate for cancer research [6].

The causes of cancer could be attributed to change in tumor suppressor genes such as p53 and PTEN protein [7] [8], to oncogene activation [9] [10] and hormonal disorders [5] [11] [12]. In addition, as is well known, survival time in dogs with malignant mammary tumors is lower when compared with those affected by benign tumors [13]. Treatment of a malignant tumor usually involves surgery. However, because of metastases, a major complication of malignant neoplasm due to common location in regional lymph nodes and lungs, chances of surgical success are directly related to the earlier diagnosis [14] [15].

To prognosis, a group of molecules called tumor markers allows visualizing small changes of proliferative disorders in cancer. The tumor proliferative activity in tissue is determined by the fraction of malignant growth and the cell cycle time. Ki-67 is a molecule associated with a high proliferative activity, which serves to indicate the potential of malignant neoplasia, and therefore to determine the limited time of patient survival [16] [17]. By flow cytometry, Ki-67 expression has been shown in all phases of the cell cycle, except $\mathrm{G}_{0}$, displaying its maximum value in prophase and metaphase [18]. Immunohistochemical identification of Ki-67 allows analyzing a greater number of cells, when compared with mitotic figure counting as only parameter to be useful in prognosis of patient survival suffering from cancer [17].

Likewise, P53 is a gene encoding a $53 \mathrm{kDa}$ protein, which is part of so-called tumor suppressor proteins. In other words, P53 is capable of inducing cellular apoptosis in biologically favorable situations [19]. In case of tumoral tissues, mutant p53 protein over-expression is observed. For recognition of p53 different epitopes, monoclonal antibodies (PAb240, PAb421) have been widely used in fixed and kept tissue in paraffin. Its applicability has been useful predicting the possible increased malignant potential and poor prognosis in canine mammary tumors [20] [21].

HER2 protein is a gene produced by a specific proto-oncogene. When presented in an excessive amount, this gene induces cells to grow faster than normal speed, thus contributing in the appearance of cancer. Cancer cells have on their surface between 10 and 100 times more HER2 receptors than normal, and both multiply in the same proportion [22] [23]. By FISH (fluorescence in situ hybridization), HER2 receptor magnitude can be analyzed in a tumor tissue sample. The result is considered positive when at least $10 \%$ of tumor cells exhibit a complete and intense staining of their membranes. HER2 positive patients have a lower percentage of response to standard treatment (chemotherapy and hormonal therapy) than negative patients [24] [25].

On the other hand, cell cycle regulation for normal tissues proliferation is based on a complex network involving cyclin dependent kinases (CDKs) and their inhibitors (CDKIs) through two main pathways of regulation: p53 and Rb1 [26]. Among the CDK inhibitory proteins are p16, p21 and p2. Its inhibition over CDK2, CDK4 
and CDK6 (involved in early G1 phase of the cell cycle) makes cells to enter at senescence, or an aging step, what is optimal for attacking cancer cells [27]. Several studies have been done by testing the expression of molecules associated with prognosis in malignant mammary neoplasms [28]. However, the relationship between molecule associated to senescence and clinical prognosis of patients affected by mammary cancer is little known. Likewise, sufficient studies to describe the expression of androgen receptors in canine mammary tumors have not been found.

Beyond a collection of data, the major interest of the present study was to carry out a clinical follow-up of patients affected by these tumors, through association with molecular markers. This allowed the establishment of a preliminary data set, also of the differences among the biological behavior of mammary neoplasms in canines around the world.

\section{Materials and Methods}

\subsection{Animals}

This study was approved by the Ethics Committee on Animal Experimentation of the Faculdade de MedicinaVeterináriaUniversity of Caldas, Manizales, Colombia. Was madea descriptive study, with 60 samples of canine mammary neoplasms, diagnosed by the Animal Pathology Laboratory of University of Caldas (Colombia,).The samples were taken from the female dog with mammary neoplasms. Samples were processed by immunohistochemistry for molecular indicators of cellular senescence, and clinical prognosis markers at Laboratory of Investigative and Comparative Pathology (FMVZ-UNESP), São Paulo, Brazil. In those patients subjected to surgery (lumpectomy, mastectomy and radical mastectomy regional), neoplastic mass size, clinical evidence of the regional lymph node lesions (axillary, inguinal and popliteal), and radiographic rating for presence of metastases, similarly as suggested by WHO [29], were reviewed. A follow-up of survival after surgery was done. From returning patients to the hospital, postoperative complication, subsequent treatments, tumor recurrence, survival time, and causes of an eventual death, were monitored.

At the end of the study, a cut point was undertaken to review the clinical histories to determine whether animals were still alive. Between 6 and 36 months after the surgery, a telephone contact with some owners was made in order to check the patient status. In surgical patients (lumpectomy, mastectomy and radical mastectomy regional) neoplastic mass size, clinical evidence of regional lymph node lesions (axillary, inguinal and popliteal), and radiographic rating for metastasic presence, similarly suggested by WHO [29], were checked. No case was diagnosed by cytology or biopsy. Because surgeons were not the same performing the procedures, results were not included and, therefore, techniques were not standardized.

\subsection{Immunohistochemistry Procedure}

The immunohistochemistry labeling included antibodies against esteroid hormone receptors (estrogen, progesterone, and androgen), molecule indicators of cell proliferation/suppression (Her-2, Ki-67, P 53), neovascularization indicators (CD-31) and molecules associated to apoptosis (P21, P16 and P27).

Blocks containing fragments of canine mammary gland were cut, processed by routine technique $\mathrm{H} \& \mathrm{E}$, and classified according to the diagnostic system proposed by Cassali et al. [30]. The Immunohistochemistry technique for detection of molecules associated to prognosis of canine mammary cancer was done according to the standard in the Laboratory of Investigative and Comparative Pathology (FMVZ/UNESP) [31].

Details of reagents used are listed in Table 1. As positive controls, archived blocks were used. For those first tested, cited literature recommendations in Table 1 were used.

As a negative control for all reactions, the addition of primary antibody was omitted, and replaced byTRIS buffer $\mathrm{pH} 7.4$.

\subsection{Statistic Analysis}

The results of immunostaining were obtained in qualitative terms of positivity, and grouped into frequencies. Positive cases were compared by means of a Student's t test $(\alpha=0.05)$. Data were analyzed using Microsoft Excel $^{\circledR}$ program 2008 for Mac, version 12.0 (071130). A correlation analysis $(\alpha=0.05)$ between clinical and histopathological variables allowed to compare them to determine the existence of indicators of clinical prognosis. 
Table 1. List of antibodies used to detect indicators of clinical prognosis associated with mammary gland tumors in dogs.

\begin{tabular}{|c|c|c|c|c|}
\hline Primary antibodies & Detection system & Type & Dilution & Reference \\
\hline Anti Estrogen Receptor & Avidin-biotin immunoperoxidase & $\begin{array}{c}\text { Mouse } \\
\text { Monoclonal }\end{array}$ & $1: 50$ & Manee-in et al. [29] \\
\hline $\begin{array}{c}\text { Anti } \\
\text { Progesterone Receptor }\end{array}$ & Avidin-biotin immunoperoxidase & $\begin{array}{c}\text { Mouse } \\
\text { Monoclonal }\end{array}$ & $1: 100$ & Manee-in et al. [29] \\
\hline $\begin{array}{c}\text { Anti } \\
\text { Androgen Receptor }\end{array}$ & Streptavidin-biotin-complex peroxidase & $\begin{array}{c}\text { Rabbit } \\
\text { Policlonal }\end{array}$ & $1: 15$ & Illera et al. [33] \\
\hline Anti p53 & $\begin{array}{l}\text { Streptavidin-biotin-complex } \\
\text { Peroxidase }\end{array}$ & $\begin{array}{l}\text { Mouse } \\
\text { Monoclonal }\end{array}$ & $1: 50$ & Kanavaros et al. [27] \\
\hline Anti-HER-2 & horseradish peroxidase-conjugated & $\begin{array}{c}\text { Rabbit } \\
\text { Policlonal }^{*}\end{array}$ & $1: 100$ & Bertagnolli et al. [34] \\
\hline Anti Ki-67 & Alkalinephosphatase/anti-alkaline phospatase & $\begin{array}{l}\text { Mouse } \\
\text { Monoclonal }\end{array}$ & $1: 20$ & Kanavaros et al. [27] \\
\hline Anti-CD31 & Avidin-biotin immunoperoxidase & $\begin{array}{c}\text { Mouse } \\
\text { Monoclonal }\end{array}$ & $1: 100$ & Kanavaros et al. [27] \\
\hline Anti-p16, p21, p27 & Horseradish peroxidase-conjugated & $\begin{array}{c}\text { Mouse } \\
\text { Monoclonal }\end{array}$ & $1: 50 ; 1: 100 ; 1: 50$ & $\begin{array}{l}\text { MacNeil et al. [35] } \\
\text { Kanavaros et al. [27] }\end{array}$ \\
\hline
\end{tabular}

*Anti human c-erbB-oncoprotein

\section{Results}

During the study period, 60 neoplasms were diagnosed, of which 55 (91.7\%) were classified as malignant, and five (8.3\%) as benign. In general terms, there were 31 cases (51.7\%) diagnosed as complex carcinoma, eight cases (13.3\%) as carcinoma in mixed tumor, cases (10.0\%) as papillary carcinoma, and the 15 remaining cases (25.0\%) with other diagnoses, majorly malignant. Details of each diagnosis can be seen in Table 2. Regarding benign neoplasms, largest presentation belonged to three mixed tumors. In addition, there were two cases, one of simple adenoma, and other of tubular adenoma.

Upon completing the study, 15 patients (25\%) survived, while 45 (75\%) died. In the case of malignant neoplasms, 40 patients died because of the illness. Conversely, in benign neoplasms, none of the five animals survived, but the death cannot attribute to causes related to the neoplastic process. Because the surgical procedures were performed at different times, the cases varied over time of clinical follow-up for postoperative survival, between 6 and 36 months (see Table 3). One female canine affected by a malignant neoplasm reached 38 months of post-surgical survival, even though, this patient died at final of the study.

Concerning the 40 patients dying by malignant neoplasms, 10 were euthanized at surgery (assuming cancer complication), 21 (52.5\%) survived less than 6 months, 7 (17.5\%) lived between 6 months and one year, and 2 of them were alive for 22 and 38 months, respectively, both with diagnosis of complex carcinoma.

About lesion distribution, 33 cases (55.0\%) were affected only in a mammary gland (including the five benign neoplasms), while 19 cases (31.7\%) had simultaneous lesion in two or more mammary glands. Eight cases (13.3\%) had no data. On the other hand, twenty-four cases were classificated as small lesions (between 0 - $3 \mathrm{~cm}$ ), including all benign neoplasms. Six female canine with small malignancies stayed alive (with until 36-month postoperative survival), and one died 38 months after surgery. For tumors whose sizes were between 3 and $5 \mathrm{~cm}$, (all malignant), nine animals were alive at the time of the research completion. For group affected by every malignant lesions larger than $6 \mathrm{~cm}$, all died at different times after surgery.

The type of surgery most used by veterinarian surgeons was the simple lumpectomy, followed by the regional mastectomy. Sentinel node was removed by surgery only when clearly affected. All female canine affected by benign neoplasms were spayed between the second and fourth year of age. In the same way, for animals affected by malignant neoplasms, seven patients were spayed prior to surgery for tumor extirpation (between 1 and 60 months), two patients on the day of mastectomy (dying 3 months after the procedure), and another patient a month after the mastectomy. Fifteen patients remained intact, while obtaining data from the rest was not possible. In general, the ages of the sick female canines ranged between 5 and 15 years. The mean age of benign tumor appearance was 10.8 years, and for malignancies was 12.7 years. 
Table 2. Benign and malignant mammary neoplasms in female canines with clinical follow-up of post-surgical survival.

\begin{tabular}{|c|c|c|c|}
\hline \multirow{2}{*}{ Diagnostic } & \multicolumn{2}{|c|}{ Clinical follow-up ${ }^{*}$} & \multirow{2}{*}{ Tota } \\
\hline & Live & Death & \\
\hline Complex carcinoma & 9 & 22 & 31 \\
\hline Carcinoma in mixed tumor & 3 & 5 & 8 \\
\hline Intraductual carcinoma & 1 & 0 & 1 \\
\hline Papillary carcinoma & 1 & 5 & 6 \\
\hline Simples carcinoma & 0 & 3 & 3 \\
\hline Solid carcinoma & 0 & 1 & 1 \\
\hline Tubular carcinoma & 0 & 2 & 2 \\
\hline Tubular papillary carcinoma & 0 & 1 & 1 \\
\hline Carcinosarcoma & 1 & 1 & 2 \\
\hline Benign mixed tumor & 0 & 3 & 3 \\
\hline Simples adenoma & 0 & 1 & 1 \\
\hline Tubular adenoma & 0 & 1 & 1 \\
\hline Total & 15 & 45 & 60 \\
\hline
\end{tabular}

*Between 6 and 36 months, after surgery.

Table 3. Time of postsurgical survival in male canine with malignant mammary tumors (analysis of 15 cases).

\begin{tabular}{ccccc}
\hline Case No. & Diagnostic & Breed & Age $^{*}$ & Time** $^{* *}$ \\
33 & Carcinoma in a mixed tumor & Labrador & 8.5 & 0.5 \\
32 & Carcinoma in a mixed tumor & Poodle & 14 & 0.6 \\
19 & Complex Carcinoma & Pit bull & 7 & 0.7 \\
38 & Complex Carcinoma & Poodle & 9 & 0.7 \\
21 & Complex Carcinoma & Mixed breed & 12 & 0.7 \\
20 & Complex Carcinoma & Poodle & 12 & 0.7 \\
13 & Complex Carcinoma & Mixed breed & 8 & 0.8 \\
14 & Complex Carcinoma & Cocker spaniel & 9.5 & 0.8 \\
4 & Complex Carcinoma & Poodle & 13 & 0.8 \\
5 & Intraductual Carcinoma & Poodle & 14 & 0.8 \\
9 & Complex Carcinoma & Poodle & 15 & 0.8 \\
40 & Carcinosarcoma & Mixed breed & 10 & 12 \\
34 & Carcinoma in a mixed tumor & Poodle & 11 & 24 \\
\hline
\end{tabular}

*Age in years at the time of enter to surgery; ${ }^{* *}$ Survival time in years after surgery (female canines who survive at the time of completing the survey). 


\section{Immunohistochemistry Marking}

Markings against steroid hormones were positive. Some cases seemingly showed stronger markings; however, labeling pattern to allow comparisons of these findings was not found. Likewise, no statistically significant difference, either to compare the benign and malignant cases or to associate the diagnosis between dead or alive canines after surgery, was established. Regarding the markings against HER2 and Ki-67 (cell proliferation), they were negative in all cases (some cases apparently resulted with positive staining, being ignored by the staining intensity or the amount of tissue involved). In adittion, no statistically significant difference, either to compare benign and malignant cases or to associate diagnosis between dead or alive patients after surgery, was obtained. The markings against P 53 (tumor suppressor) and CD31 (neovascularization) were all positives. Morover, there was no statistically significant difference, either to compare benign and malignant cases, or to link diagnosis between dead or alive individuals after surgery. No statistical differences were found in immunomarcation for the different antigens used as clinical prognosis factors in mammary neoplasms. On the other hand, many differences among other clinical variables such as race, type of histopathological diagnosis, reproductive status and age were found. However, as spoken in the discussion, the approach of research does not allow taking into account these differences, since other variables interfering with the results were not controlled.

Finally, markings against molecules associated with cellular senescence (apoptosis) were all positives and, again, some seemed to have cases with stronger markings (See Figure 1). Nevertheless, as been said, a labeling pattern allowing comparisons of these findings was not assesed. As has been confirmed, there is no statistically significant difference, either to compare the benign and malignant cases, or to associate between dead or alive specimens after surgery. This allows concluding about its predictive value in the prognosis of cases.

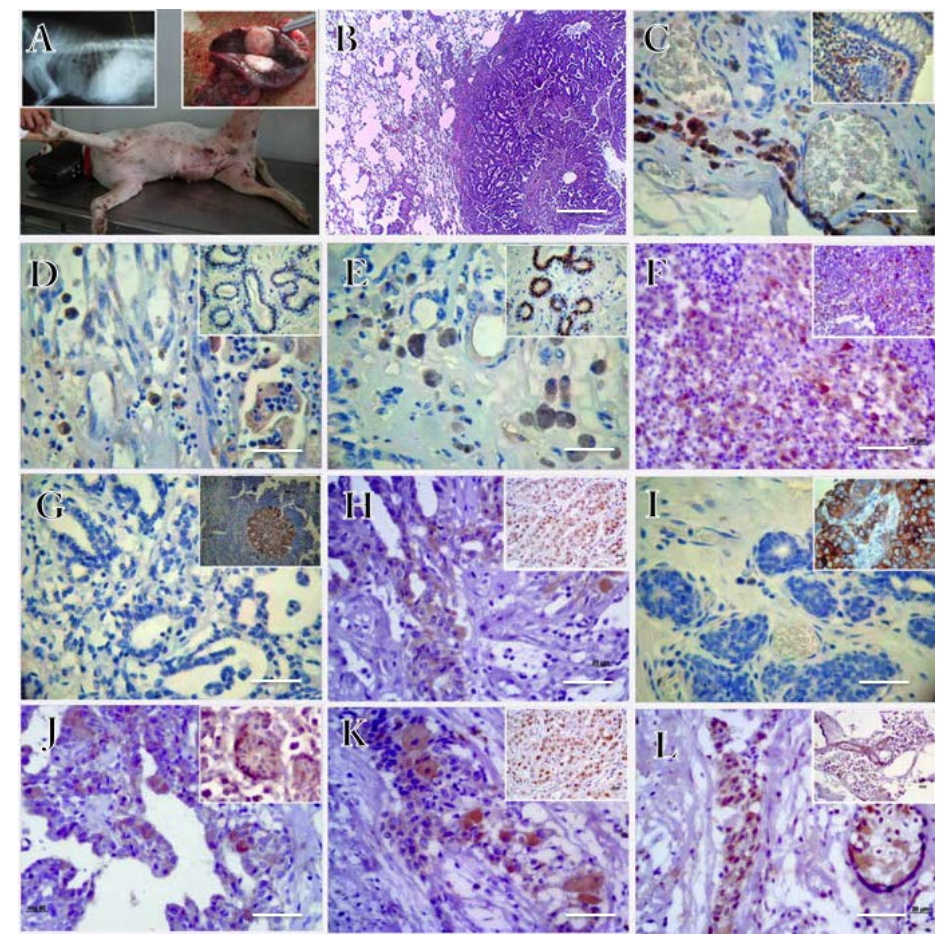

Figure 1. (A) Female canine affected by malignant mammary neoplasia. The upper left box shows the chest radiograph (with metastase) as part of the clinical evaluation. In the upper right frame, the sentinel lymph node metastasis visibly lesioned (obtained at necropsy); (B) Histopathological image of a breast carcinoma metastasis to lung, hematoxylin and eosin staining. In the following images, at upper left of each box, its positive control is observed; (C) Immunohistochemical marker against CD31 receptor, Bar = $50 \mu \mathrm{m}$; (D) Immunohistochemical marker against Estrogen receptor, Bar = $50 \mu \mathrm{m}$; (E) Immunohistochemical marker against Progesterone receptor, Bar $=50 \mu \mathrm{m}$; (F) Immunohistochemical marker against Androgen receptor, Bar $=50 \mu \mathrm{m}$; (G) Immunohistochemical marker against Ki67 receptor, Bar $=50 \mu \mathrm{m}$; (H) Immunohistochemical marker against P53 receptor, Bar $=50 \mu \mathrm{m}$; (I) Immunohistochemical marker against Her-2 receptor, Bar = $50 \mu \mathrm{m}$; (J) Immunohistochemical marker against P21 receptor, Bar $=50 \mu \mathrm{m}$; $(\mathrm{K})$ Immunohistochemical marker against P16 receptor, Bar $=50 \mu \mathrm{m}$; (L) Immunohistochemical marker against P27 receptor, Bar $=50 \mu \mathrm{m}$. 


\section{Discussion}

In this group of dogs with mammary cancer, tumor size, histological pattern and intravascular growth had more impact in the study of the aspects related to prognostic factors. However, at last, no statistical significance among analyzed patients was found. The determination of sentinel lymph node status was not possible by inadequate clinical case management. In fact, concerning veterinary activity around the world, a deficit in this regard is well known. Nevertheless, when examining the possibility of interrelationship between these factors, a multivariate analysis in stages was performed in order to identify independent prognostic factors. This allowed to confirme the independent prognostic value of tumor size and histologic grade.

The analysis of prognostic power of immunomarkers was not maintained in the multivariate analysis after the "tumor size" and "histological grade" variables were introduced, meaning that the survival of patients was more dependent on them. The occurrence frequency of mammary tumors in dogs indicates that about half of them are malignant [32].

In the present investigation, carcinoma was more frequent. This coincides with other authors in Colombia, when holding that malignancies occur in greater proportion [2] [33]. The way to get cancer frequency data varies worldwide. In Colombia and many regions of Brazil, clinical diagnosis still prevails over histopathological diagnosis, at the expense of the decision to perform an adequate surgical treatment, also favoring disease underreporting. In this study, the post-surgical death of animals with benign affections was not attributed to breast disease, when proved to be secondary after necropsia, in comparison with other entities such as endocrinopathies and metabolic diseases. Since animals affected by malignant neoplasms were the only survivors at the end of the research, the post-surgical survival analysis was limited to them. The animals survived between 0.5 and 36 months after surgery, in most cases limited to removing the affected tissues. In this way, surgical treatment emerges a recommended veterinarian procedure to some individuals.

Erasoand Cruz [34], report similar data when finding, after a year of the last mastectomy, almost half of patients stayed alive (one-third of those affected by malignant neoplasms, whereas dead animals, two thirds had this condition). Studies of post-surgical survival in dogs are scarce. However, they are key to understand the biological behavior of mammary tumors, and to establish programs of disease control in canines.

In our study, a good number of animals remain alive, even 36 months after surgery. This time can be considered high taking into account the lack of surgical technique standarization, besides of unperformed adenectomy (at least in some patients). Its comparison with other studies is challenging because of differences in estimating risk populations, inclusion criteria, and neoplasm diagnosis and classification. Within the veterinary community, the agreement to use a specific international classification is necessary. So far, the suggestion made by Casali et al. [30], provides an excellent alternative to organize histopathological diagnosis, and to compare the results of the investigation. In the present study, the use of this nomenclature facilitates analysis, creating a commitment to collect international data. Eventually, it will be helpful to establish a national registry of cancer in animals, which would allow comparison with studies done elsewhere.

On the other hand, regarding most affected breeds by breast tumors, some authors address high susceptibility of French Poodle, Boston Terriers, Samoyeds, Boxer, and Cockers [35] [36]. The present study did not focuse on the proportional morbidity of any breed. Nevertheless, Murillo et al. [37], carried out a research only at Teach Animal Hospital, which concluded whether French Poodle was the more abundant breed, the chance of finding patients suffering from cancer also was higher [38]. Analyzing the postoperative survival of pure dog against mestizo, last breed was apparently the more affected, with only $18.7 \%(3 / 16)$ surviving at the end, while $27.2 \%(12 / 44)$ of pure animals remained alive at the same circumstance.

In the final analysis, there were no significant breed differences as an influential prognostic factor on canine mammary cancer. The disease evolution time and the neoplastic mass size were demanding parameters to analyze because of variations on patient admission to the study. In other words, coincidence in the evolution time was not found, which can oscilate from few months to two years. At this point, time is highly probable to be greater than reported by owners during consultation. This suggests that the size of the lesions could be related to the prognosis of postoperative survival, perhaps, due to the ease of small mass removal.

In our study, the survival of some patients is likely to be a consequence of having extracted the sentinel lymph node. Thus, the "less aggressive" behavior cannot necessarily be attributed to diagnosis as such. The performed surgery type is fundamental to the subsistence of the patient. This open the discussion on the need to educate owner about a faster veterinary consult, once neoplastic masses are detected in pets. 
In the present investigation, no case was submitted to bilateral radical mastectomy, being considered very invasive and of high degree of difficulty to surgical management. In cases of performed nodulectomy, many animals with malignant diagnosis survived, while cases submitted to mastectomy, nearly half died after the surgical procedure.

In the same sense, standardization of clinical diagnostic procedures to assess lesions on sentinel lymph node is necessary. Being the lymphatic drainage the most common route to metastasis, microscopic evaluation of the lymph nodes may play a vital role to treatment decision, becoming an important prognostic factor. In dogs, a controversy regarding the adenectomy, as an additional technique for surgical treatment of breast cancer, still exists. However, the main difficulty of some cases is related to breast drainage site location. Adenectomy can ensure limitation of metastasis. In humans, a supravital marker is used to show the corresponding lymph nodes in each tumor in order to avoid leaving neoplasia residue on the patient [39].

In this research, estrogen and progesterone receptors were well evidenced by using antibodies against human tissue. On the other hand, significant difference about its presentation was not obtained. Androgen receptors were present in almost all cases, with an apparent better dial in malignant diagnosis cases, but without statistical difference. Regarding the P53, despite its positivity, establishing whether the lesion sizes or their duration can influence the expression of these molecules could not be possible. However, for further clinical monitoring, inclusion of information from these variables to enhance the knowledge is necessary. A major hardship to analyse cases from the present study is related to the negativity of cell proliferation markers (HER-2 and Ki-67). In addition, some problems linked to the antibody efectiveness in dogs (although its use has been reported in literature), or to the demanding nature of some procedure steps as antigen retrieval for these markers (samples spent several days in formalin acid) could have affected.

On the other hand, many cases were strongly marked for CD 31 indicating abundant neovascularization, occurring to both malignant and benign neoplasms, without notable difference (benign cases were very few which prevented a proper comparison of CD 31expression and other markers). In addition, differences between dead and live animals were not found.

A breakthrough in the immunostaining of cancer-associated molecules was the positivity of cell senescence markers. Although significant difference in its expression was not found, coloration was apparently stronger in patients surviving until the end of the study. In a new study, the clinical follow-up could control more variables (for instance, a prospective study) to explore immunostaining differences of these molecules, which may be useful as prognostic indicators for breast cancer.

\section{Conclusion}

According to the study conditions, the survival of patients affected by breast tumors is directly related to diagnosis and malignancy histological grade, but not to animal breed, number of affected glands or patient reproductive status. On the other hand, immunohistochemical markings were not related to the patient prognosis. For this reason, it is important to highlight the persistance of a high percentage of mammary neoplasm cases clinically diagnosed with poor results on patient survival. Thus, educating owners and veterinarians for using diagnostic available tools to improve the prognosis after surgical animals affected by breast cancer is quite necessary.

\section{Authors' Contributions}

Design of the study: NSR, FPO. Coordination of the study: NSR. Collection samples: FJP. Immunohistochemical analysis: LMMF, FPO. Statistical analysis and elaboration of manuscript: FJP. Critical review of the manuscript: NSR, LMMF, CB. All authors read and approved the final manuscript.

\section{Acknowledgements and Funding}

The authors of this paper acknowledge to the Sao Paulo Research Foundation (FAPESP), Brazil, which provided financial support for Francisco Pedraza-Ordoñez through the Post-doctoral Fellowship2011/23737-3. Likewise, to Universidad de Caldas and Universidade Estadual Paulista, which contributed with essential materials for this study and to Prof. Wismar Sarmiento for his valuable help in the text edition.

\section{Competing Interests}

None of the authors of the present document has conflict of interest for its publication. 


\section{References}

[1] Munson, L. and Moresco, A. (2007) Comparative Pathology of Mammary Gland Cancers in Domestic and Wild Animals. Breast Disease, 28, 7-21.

[2] Torres, G. and Botero, L. (2008) Estudio histopatológico retrospectivo de neoplasias de glándula mamaria en caninos (1975-2000). Revista Orinoquia, 12, 80-88.

[3] Vásquez, T., Krygier, G., Barrios, E., Cataldi, S., Vázquez, A., Alonso, R., Estellano, F., Folle, E., Laviña, R., Delgado, F. and Pressa, C. (2005) Análisis de sobrevida de una población con cáncer de mama y su relación con factores pronósticos: estudio de 1.311 pacientes seguidas durante 230 meses. Revista Médica del Uruguay, 21, 107-121.

[4] Pardo, C. and Murillo, M. (2002) Casos nuevos de cancer en el Instituto Nacional de Cancerologia Colombia. Revista Colombiana de Cancerologia, 7, 4-19.

[5] Kumaraguruparan, R., Prathiba, D. and Nagini, S. (2006) Of Humans and Canines: Immunohistochemical Analysis of PCNA, Bcl-2, p53, Cytokeratin and ER in Mammary Tumors. Research in Veterinary Science, 81, 218-224. http://dx.doi.org/10.1016/j.rvsc.2005.08.002

[6] Uva, P., Aurisicchio, L., Watters, J., Loboda, A., Kulkarni, A., Castle, J., Palombo, F., Viti, V., Mesiti, G., Zappulli, V., Marconato, L., Abramo, F., Ciliberto, G., Lahm, A., La Monica, N. and Rinaldis, E. (2009) Comparative Expression Pathway Analysis of Human and Canine Mammary Tumors. BMC Genomics, 10, 135. http://dx.doi.org/10.1186/1471-2164-10-135

[7] Kanae, Y., Endoh, D., Yocota, H., Taniyama, H. and Hayashi, M. (2006) Expression of the PTEN Tumor Suppressor Gene in Malignant Mammary Gland Tumors of Dogs. American Journal of Veterinary Research, 67, 127-133. http://dx.doi.org/10.2460/ajvr.67.1.127

[8] Lee, C., Kim, W., Lim, J., Kang, M., Kim, D. and Kweon, K. (2004) Mutation and Overexpression of p53 as a Prognostic Factor in Canine Mammary Tumors. Journal of Veterinary Science, 5, 63-69. http://dx.doi.org/10.1292/jvms.66.63

[9] Klopfleisch, R. and Gruber, A. (2009) Differential Expression of Cell Cycle Regulators p21, p27 and p53 in Metastasizing Canine Mammary Adenocarcinomas versus Normal Mammary Glands. Research in Veterinary Science, 87, 91-96. http://dx.doi.org/10.1016/j.rvsc.2008.12.010

[10] Zaidan, M. (2008) The Search Suitable Pronostic Markers for Canine Mammary Tumors: A Promising Outlook. The Veterinary Journal, 177, 3-5. http://dx.doi.org/10.1016/j.tvjl.2007.10.015

[11] Millanta, F., Silvestri, G., Vaselli, C., Citi, S., Pisani, G., Lorenzi, D. and Poli, A. (2006) The Role of Vascular Endothelial Growth Factor and Its Receptor Flk/KDR in Promoting Tumour Angiogenesis in Feline and Canine Mammary Carcinomas: A Preliminary Study of Autocrine and Paracrine Loops. Research in Veterinary Science, 81, 350-357. http://dx.doi.org/10.1016/j.rvsc.2006.01.007

[12] De lasMulas, J.M., Millan, Y. and Dios, R. (2005) A Prospective Analysis of Immunohistochemically Determined Estrogen Receptor $\alpha$ and Progesterone Receptor Expression and Host and Tumor Factors as Predictors of Disease Free Period in Mammary Tumors of the Dog. Veterinary Pathology, 42, 200-212. http://dx.doi.org/10.1354/vp.42-2-200

[13] Sorenmo, K. (2003) Canine Mammary Gland Tumors. Veterinary Clinics of North America: Small Animal Practice, 33, 573-596. http://dx.doi.org/10.1016/S0195-5616(03)00020-2

[14] Novasad, A.C. (2003) Principles of Treatment for Mammary Gland Tumors. Clinical Techniques in Small Animal Practice, 18, 107-109. http://dx.doi.org/10.1053/svms.2003.36625

[15] Whithrow, J. and Vail, D. (2007) Small Animal Clinical Oncology. 4th Edition, Elsevier, St. Louis.

[16] Nieto, A., Perez-Alenza, M.D., Del Castillo, N., Tabanera, E., Castano, M. and Pena, L. (2003) BRCA1 Expression in Canine Mammary Dysplasias and Tumors: Relationship with Prognostic Variables. Journal of Comparative Pathology, 128, 260-268. http://dx.doi.org/10.1053/jcpa.2002.0631

[17] Löhr, C.V., Teifke, J.P., Failing, K. and Weiss, E. (1997) Charaterization of the Proliferation State in Canine Mammary Tumors by Standardized AgNOR Method with Postfixation and Inmunohistologic Detection of Ki-67 and PCNA. Veterinary Pathology, 34, 212-221. http://dx.doi.org/10.1177/030098589703400306

[18] Peña, L.L., Nieto, A.I., Pérez-Alenza, D., Cuesta, P. and Castãno, M. (1998) Immunohistochemical Detection of Ki-67 and PCNA in Canine Mammary Tumors: Relationship to Clinical and Pathologic Variables. Journal of Veterinary Diagnostic Investigation, 10, 237-246. http://dx.doi.org/10.1177/104063879801000303

[19] Greenblatt, M.S., Bennett, W.P., Hollstein, M. and Harris, C.C. (1994) Mutations in the p53 Tumor Suppressor Gene: Clues to Cancer Etiology and Molecular Pathogenesis. Cancer Research, 54, 4855-4878.

[20] Chung-Ho, L., Wan-Hee, K., Ji-Hey, L., Min-Soo, K., Dae-Yong, K. and Oh-Kyeong, K. (2004) Mutation and Overexpression of p53 as a Prognostic Factor in Canine Mammary Tumors. Journal of Veterinary Science, 5, 63-69.

[21] Veldhoen, N., Watterson, J., Brash, M. and Milner, J. (1999) Identification of Tumour-Associated and Germ Line p53 
Mutations in Canine Mammary Cancer. British Journal of Cancer, 81, 409-415. http://dx.doi.org/10.1038/sj.bjc.6690709

[22] Ahad, M., Elahe, K., Pejman, M., Farkhondeh, B. and Iraj, S.H. (2012) Overexpression of HER-2/neu in Malignant Mammary Tumors; Translation of Clinicopathological Features from Dog to Human. Asian Pacific Journal of Cancer Prevention, 13, 6415-6421. http://dx.doi.org/10.7314/APJCP.2012.13.12.6415

[23] Millanta, F., Calandrella, M., Bari, G., Niccolini, M., Vannozzi, I. and Poli, A. (2005) Comparison of Steroid Receptor Expression in Normal, Dysplastic and Neoplastic Canine and Feline Mammary Tissues. Research in Veterinary Science, 79, 225-232. http://dx.doi.org/10.1016/j.rvsc.2005.02.002

[24] Dutra, A.P., Granja, N.V., Schmitt, F.C. and Cassali, G.D. (2004) C-erbB-2 Expression and Nuclear Pleomorphism in Canine Mammary Tumors. Brazilian Journal of Medical and Biological Research, 37, 1673-1681. http://dx.doi.org/10.1590/S0100-879X2004001100013

[25] Yang, Q., Mori, I., Sakurai, T., Yoshimura, G., Suzuma, T., Nakamura, Y., Nakamura, M., Taniguchi, E., Tamaki, T., Umemura, T. and Kakudo, K. (2001) Correlation between Nuclear Grade and Biological Prognostic Variables in Invasive Breast Cancer. Breast Cancer, 8, 105-110. http://dx.doi.org/10.1007/BF02967488

[26] Kanavaros, P., Stefanaki, K., Rontogianni, D., Papalazarou, D,, Sgantzos, M., Arvanitis, D., Vamvouka, C., Gorgoulis, V., Siatitsas, I., Agnantis, N.J. and Bai, M. (2001) Immunohistochemical Expression of p53, p21/Waf1, rb, p16, Cyclin D1, p27, Ki67, Cyclin A, Cyclin B1, bcl2, Bax and Bak Proteins and Apoptotic Index in Normal Thymus. Histology and Histopathology, 16, 1005-1012.

[27] Serrano, M. (2010) A Lower Bar for Senescence. Nature, 464, 363-364. http://dx.doi.org/10.1038/464363a

[28] Manee-in, S., Sayamon, S., Chainarong, L. and Sudson, S. (2009) The Number of ER $\alpha$ and PR in the Mammary Glands of Bitches with and without Tumor Mass Using Immunohistochemical Assay. Comparative Clinical Pathology, 18, 221-227. http://dx.doi.org/10.1007/s00580-008-0786-3

[29] Slatter, D. (2003) Textbook of Small Animal Surgery. 3rd Edition, Saunders, Philadelphia.

[30] Cassali, G.D., Lavalle, G.E., De Nardi, A.B., Ferreira, E., Bertagnolli, A.C. and Estrela-Lima, A. (2011) Consensus for the Diagnosis, Prognosis and Treatment of Canine Mammary Tumors. Brazilian Journal of Veterinary Pathology, 4, 153-180.

[31] Semenzati, G.O., Martins, R.H.G., Salgado, B.S. and Rocha, N.S. (2012) Matheus SMM: Histological and Immunohistochemical Study of the Expression of p53 and Ki-67 Proteins in the Mucosa of the Tongue, Pharynx and Larynx of Rats Exposed to Cigarette Smoke. Inhalation Toxicology, 24, 723-731. http://dx.doi.org/10.3109/08958378.2012.715317

[32] Bonagura, J.D. and Twedt, D.C. (2009) KIRKTerapeutica Veterinaria Actual XIV. Elsevier, Barcelona.

[33] Ferreira, G.M., Pedraza, F.J. and Arango, M. (1997) Neoplasias de glandula mamaria canina diagnosticadas en Medellín, Colombia, entre 1968 y 1994. Veterinaria México, 28, 257-259.

[34] Eraso, M.F. and Cruz, J.M. (2009) Sobrevida postmastectomia en hembras caninas con tumores mamarios maligno. Revista Colombiana de Ciencias Pecuarias, 22, 405.

[35] Moulton, J.E. (1990) Tumors in Domestic Animals. 3rd Edition, University of California Press, Berkley.

[36] Fossum, T.H. (2009) Cirugia en Pequeños Animales: 3ra Edition, Elsevier, Barcelona.

[37] Murillo, S.M., Pedraza, F.J. and Ferreira, G. (2008) Analisis retrospectivo de 124 casos de neoplasia mamaria en caninos de la ciudad de Manizales. Veterinaria y Zootecnia, 2, 21-28.

[38] Thrusfield, M.V. (2010) Ageing in Animal Populations-An Epidemiological Perspective. Journal of Comparative Pathology, 142, S22-S32. http://dx.doi.org/10.1016/j.jcpa.2009.10.014

[39] Pinheiro, L.P., Oliveira, R.S., Vasques, H.D., Filgueira, P.H., Aragão, D.H., Barbosa, P.M., Beserra, H.E. and Cavalcante, R.V. (2009) Hemosiderin: A New Marker for Sentinel Lymph Node Identification. Acta Cirurgica Brasileira, 24, 432-436. http://dx.doi.org/10.1590/S0102-86502009000600002 